\title{
Investigation of effects of neurotrophic factors on painful diabetic neuropathy: an experimental study
}

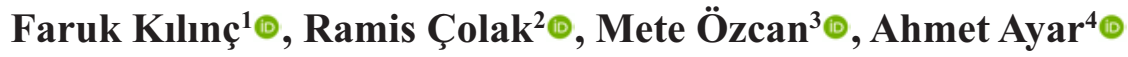 \\ ${ }^{1}$ Department of Endocrinology, Firat University School of Medicine, Elazı $\breve{g}$, Turkey \\ ${ }^{2}$ Department of Endocrinology, Ondokuz Mayls University School of Medicine, Samsun, Turkey \\ ${ }^{3}$ Department of Physiology, Firat University School of Medicine, Elazlğ. Turkey \\ ${ }^{4}$ Department of Physiology, Karadeniz Technical University School of Medicine, Trabzon, Turkey
}

DOI: $10.18621 /$ eurj.414105

\begin{abstract}
Objective: We have studied the effects of neurotrophin-4 (NT-4) different doses on the pain levels of streptozocin-induced diabetic rats.

Methods: Thirty-five 3-week-old male rats were used. After induction of diabetes in rats with streptozocin (nearly 4 weeks); diabetic animals were divided into 4 groups. The first group; healthy control group $(\mathrm{n}=15)$, the second group; diabetic control group $(\mathrm{n}=10)$, the third group; low dose $(0.3 \mathrm{mg} / \mathrm{kg})$ recombinant human NT-4 was applied $(n=4)$ and the fourth group; high dose recombinant human NT-4 was applied $(n=6)$.

Results: In the low-dose NT-4 group, the pain threshold values did not differ from the diabetic control and healthy control groups. In the high dose NT-4 group, a rise was observed in the pain threshold values of hot plate in comparison with the healthy control group, diabetic control group and low dose applied group and this rise reached at the level of statistical significance $(p<0.05)$.

Conclusion: Neurotrophic factors (neurotrophin-4) have been shown to be effective on painful diabetic neuropathy in streptozocin-induced diabetic rats. However, there is a need for larger-scale and longer-term studies for clinical use.
\end{abstract}

Keywords: Diabetic neuropathy, hot plate, neurotrophin-4, streptozocin

Received: April 10, 2018; Accepted: June 11, 2018; Published Online: August 7, 2018

D iabetes mellitus (DM) is a chronic metabolicdisorder characterized by hyperglycemia that caused by a defect in insulin secretion, insulin action, or both; this results in carbohydrate, lipid, and protein metabolism disorders; accelerated atherosclerosis; and microvascular and macrovascular complications [1].

Diabetic neuropathy is a clinically or subclinically detectable disorder of the somatic or autonomous parts of the peripheral nervous system occurring in the presence of DM [2].

Diabetic neuropathy is the most frequent cause of neuropathy in developed countries, and it accounts for $50-75 \%$ of non-traumatic amputations. It is the most important cause in the etiology of diabetic foot problems [2].

Neurotrophic factors are small proteins supporting the survival and growth of neurons [3]. These factors constitute the neurotrophin (NT) group of pro-

Address for correspondence: Faruk Kllınç, MD., Assistant Professor, Firat University School of Medicine, Department of Endocrinology, 23100, Elazığ, Turkey

E-mail:drfarukkilinc@hotmail.com,Tel:+90 4242333555 (2453)Fax:+90424233 3558 
teins involving nerve growth factor (NGF), NT-3, brain-derived neurotrophic factor (BDNF), and NT$4 / 5$. These molecules ensure the development, differentiation, and maintenance of the nervous system. Recent studies have demonstrated impaired NT support in DM and have suggested that this contributes to diabetic neuropathy pathogenesis $[4,5]$.

The demonstration of the neuroprotective roles of neurotrophic factors against damage to sensory neurons has necessitated testing the effectiveness of these agents for treating neuropathic pain. Among these agents, glial cell line-derived neurotrophic factor has been demonstrated to exert analgesic effects by suppressing ectopic afferent activity and has been used for treating experimentally induced neuropathy [4-7]. Glial cell line-derived neurotrophic factor has been effectively used in the treatment of an experimental mice model of diabetic neuropathy; however, the efficacy of the recently discovered agents has not been tested [8].

In the present study, the effects of different doses of NT-4 on hot plate pain threshold values were investigated to examine the effects of neurotrophic factors on painful diabetic neuropathy in streptozotocin (STZ)-induced diabetic mice.

\section{METHODS}

This study was conducted at Frat University Experimental Research Center in collaboration with the Department of Physiology at Firat University Faculty of Medicine, and approval was obtained from Frrat University Animal Studies Ethics Committee (Project no: 1667).

\section{Laboratory Animals}

Male BALB-C mice used in the experiments were supplied from Firat University Experimental Research Center.

\section{Diabetes Induction}

Totally, $180 \mathrm{mg} / \mathrm{kg}$ of STZ (Pharmacia, France) was dissolved in $0.4 \mathrm{ml}(0.1 \mathrm{M})$ sodiumcitrate buffer $(\mathrm{pH}: 4.5)$ and intraperitoneally administered as a single injection usinga 26-gauge insulin injector to induce diabetes in 35 mice [9]. By sampling blood from the tail area after one week, mice with postprandial blood glucose levels of $>400 \mathrm{mg} / \mathrm{dL}$ measured using a glucose meter were considered diabetic.

\section{Groups}

A total of 35 mice were used. Our study consisted of 4 groups in total. Group 1 was designated as the healthy control group, whereas groups 2,3 , and 4 were designated as the experimental groups. Four groups were created as follows:

Group $1(n=15)$ : Healthy control group.

Group $2(\mathbf{n}=\mathbf{1 0})$ : Diabetic control group

Group $3(n=4)$ : Low-dose group: Group treated with low dose-recombinant human NT-4

Group $4(n=6)$ : High-dose group: Group treated with high-dose recombinant human NT-4.

Approximately $90 \%$ of mice in the control group and the experimental groups completed the study.hree mice with a blood glucose level exceeding $500 \mathrm{mg} / \mathrm{dL}$ were excluded. Symptoms of hyperglycemia such as drinking excessive water, frequently urinating, and consuming more food were observed in STZ-treated mice. Approximately $90 \%$ of mice in the control group and the experimental groups completed the study. Three mice with a blood glucose level exceeding 500 $\mathrm{mg} / \mathrm{dL}$ were excluded. Symptoms of hyperglycemia such as drinking excessive water, frequently urinating, and consuming more food were observed in STZtreated mice. Initially, the pre-injection pain threshold values of mice were measured. Following these procedures, the animals in the control group received an intraperitoneal injection of normal saline; low dose recombinant human NT-4 $(0.3 \mathrm{mg} / \mathrm{kg})$, high dose recombinant human NT-4 (3 mg/kg), respectively. The time of injection was set at $0 \mathrm{~min}$, and pain thresholds in all groups were measured with 1-h intervals. This procedure was followed in all groups for $24 \mathrm{~h}$. The pain threshold values were measured every $24 \mathrm{~h}$ for 6 days to monitor the induction of chronic neuropathic pain and evaluate the response of chronic diabetic neuropathy to neurotrophic factors in mice within the diabetic control group and low- and high-dose groups.

\section{Hot Plate Test}

The hot plate test is an indirect indicator of acute thermal hyperalgesia. It is a thermal acute pain model 


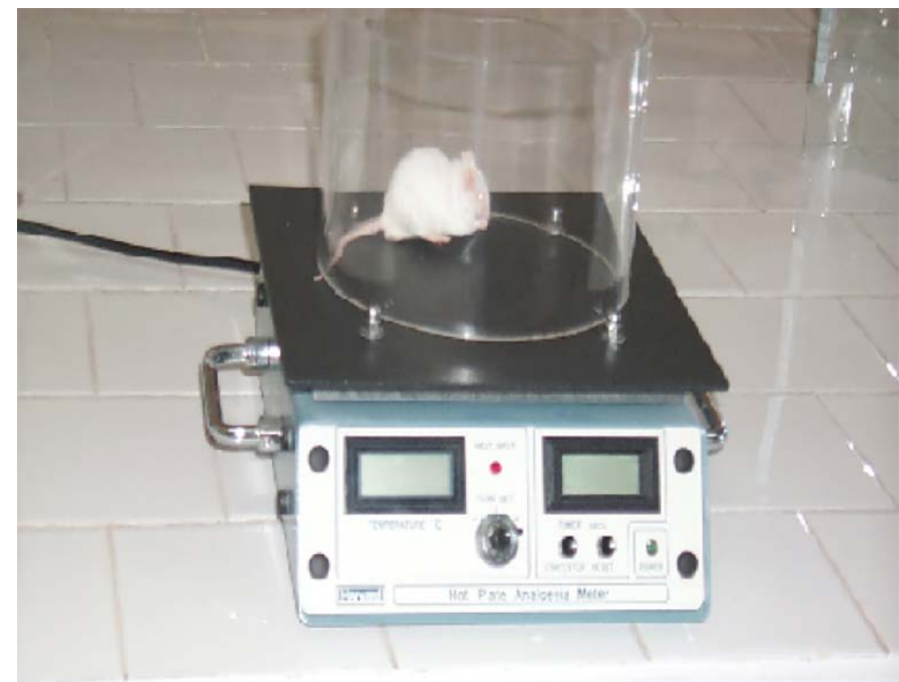

Figure 1. A harvard hot plate analgesia meter (Edenbridge, England) [10].

that examines the pain threshold by measuring the latency of an animal placed on a hot surface to heat stimulus. The appropriate size hot plate analgesia meter (Harvard, Edenbridge, UK) was used to provide easy mobility for the rats in the study (Figure 1). The test was performed by placing the mice on the platepreset to $50 \pm 0.5^{\circ} \mathrm{C}$ and surrounded with a transparent plastic barrier confining the animal to the test area. The latency time to behavioral responses to the heat stimulus after placing the mice on the hot surface was measured. In this study, behavioral responses tothe heat stimulus indicating the pain threshold were defined as forepaw licking, forepaw lifting, or jumping.

\section{Statistical Analysis}

Statistical analyses were performed using SPSS 12.0, and charts were constructed using Microsoft Office 2003 Excel. One-way analysis of variance was used along with Student's t-test and Fisher's PLSD post hoc test for the statistical analysis ofstudy data. Descriptive statistics were expressed in the form of cross tabulations for categorical variables, and in mean, median, standard deviation (SD), minimum, and maximum for numeric variables. The Bonferroni test was performed following one-way analysis of variance to compare the diabetic control group with the low- and high-dose groups. Independent Student's t-test was performed between the control group and the diabetic control group. Variances within same group at different time points were evaluated usingStudent's t-test for paired groups. In all analyses, a $p$ value of less than 0.05 was considered statistically significant.

\section{RESULTS}

Weekly blood glucose levels in blood samples obtained from the tail vein inthe experimental groups are shown in Table 1. During the experiment, blood glucose levels were notlower than $300 \mathrm{mg} / \mathrm{dL}$ in the weekly measurements inthe three experimental groups. Three mice with a blood glucose level exceeding $500 \mathrm{mg} / \mathrm{dL}$ were excluded.

Measurements were complete in one week. A significant difference was not observed in pain threshold values between days 1 and 7 . The mean pain

Table 1. Weekly mean blood glucose levels in the experimental groups

\begin{tabular}{lccc}
\hline \multirow{2}{*}{ Weeks } & \multicolumn{3}{c}{ Mean Blood Glucose Levels (mg/dL) } \\
\cline { 2 - 4 } & Diabetic control group & Low-dose group & High-dose group \\
\hline Week 1 & 414.57 & 417.25 & 363.2 \\
Week 2 & 389.44 & 401.45 & 415.52 \\
Week 3 & 412.36 & 394.24 & 386.52 \\
Week 4 & 371.27 & 425.54 & 415.32 \\
Week 5 & 428.56 & 412.68 & 406.55 \\
Week 6 & 438.74 & 429.27 & 411.54 \\
Week 7 & 446.27 & 432.36 & 438.71 \\
\hline
\end{tabular}


Table 2. Pain threshold values in the control group and diabetic control group. Effects of normal saline and neurotrophin-4 (NT-4) administration in mice.

\begin{tabular}{|c|c|c|c|c|}
\hline \multirow{2}{*}{ Time } & \multicolumn{4}{|c|}{ Pain Threshold Values } \\
\hline & $\begin{array}{l}\text { Healthy control } \\
\text { group }\end{array}$ & $\begin{array}{c}\text { Diabetic control } \\
\text { group }\end{array}$ & Low-dose group & High-dose group \\
\hline $\mathbf{0 ~ h}$ & $20.23 \pm 0.72$ & $20.46 \pm 1.63$ & $23.15 \pm 2.16$ & $18.65 \pm 1.45$ \\
\hline $1 \mathrm{~h}$ & $19.87 \pm 0.43$ & $19.45 \pm 1.33$ & $\begin{array}{c}29.98 \pm 2.49 \\
\mathbf{( 0 . 0 0 2 )}^{\mathbf{a}} \\
\mathbf{( 0 . 0 0 9 )}^{\mathbf{b}}\end{array}$ & $19.30 \pm 1.86$ \\
\hline $3 \mathbf{h}$ & $19.68 \pm 0.39$ & $22.65 \pm 2.13$ & $23.92 \pm 2.59$ & $19.98 \pm 0.53$ \\
\hline $6 \mathrm{~h}$ & $18.57 \pm 0.58$ & $20.12 \pm 1.28$ & $26.60 \pm 3.18$ & $19.63 \pm 0.44$ \\
\hline $24 \mathrm{~h}$ & $19.22 \pm 0.32$ & $18.79 \pm 1.49$ & $\begin{array}{c}24.78 \pm 1.19 \\
\mathbf{( 0 . 0 2 6 )}^{\mathbf{a}}\end{array}$ & $20.35 \pm 1.23$ \\
\hline Day 2 & & $18.62 \pm 1.62$ & $\begin{array}{c}25.02 \pm 1.14 \\
(\mathbf{0 . 0 2 1})^{\mathbf{a}}\end{array}$ & $19.98 \pm 0.61$ \\
\hline Day 3 & & $18.24 \pm 1.24$ & $\begin{array}{c}22.83 \pm 1.19 \\
\mathbf{( 0 . 0 4 5 )}^{\mathbf{a}}\end{array}$ & $19.45 \pm 0.50$ \\
\hline Day 4 & & $18.46 \pm 1.27$ & $\begin{array}{c}23.65 \pm 0.65 \\
(\mathbf{0 . 0 2})^{\mathrm{a}}\end{array}$ & $20.68 \pm 1.64$ \\
\hline Day 5 & & $18.07 \pm 1.46$ & $\begin{array}{l}26.23 \pm 2.25 \\
\quad(0.008)^{\mathrm{a}}\end{array}$ & $20.55 \pm 0.38$ \\
\hline Day 6 & & $19.47 \pm 1.11$ & $\begin{array}{c}25.57 \pm 1.05 \\
\mathbf{( 0 . 0 0 5 )}^{\mathbf{a}} \\
\mathbf{( 0 . 0 4 1 )}^{\mathbf{b}}\end{array}$ & $19.90 \pm 1.57$ \\
\hline Day 7 & & $18.89 \pm 0.99$ & $\begin{array}{c}25.52 \pm 1.35 \\
\mathbf{( 0 . 0 0 1 )}^{\mathbf{a}} \\
\mathbf{( 0 . 0 4 9 )}^{\mathbf{b}}\end{array}$ & $20.45 \pm 0.49$ \\
\hline
\end{tabular}

\footnotetext{
Data are shown mean \pm standard deviation.

${ }^{a}$ Significant difference compared to the diabetic control group $(p<0.05)$

${ }^{\mathrm{b}}$ Significant difference compared to the low-dose group $(p<0.05)$
}

threshold values were $24.78 \pm 1.19$ at $24 \mathrm{~h}$ and 25.52 \pm 1.35 at day 7 in the high-dose group and $20.35 \pm$ 1.23 at $24 \mathrm{~h}$ and $20.45 \pm 0.49$ at day 7 in the low-dose group $(p=0.001)(p<0.05$; Table 2, Figure 2$)$.

The mean pain threshold values in the healthy control group were $20.23 \pm 0.72 \mathrm{~s}, 19.87 \pm 0.43 \mathrm{~s}$, $19.68 \pm 0.39 \mathrm{~s}, 18.57 \pm 0.58 \mathrm{~s}$, and $19.22 \pm 0.32 \mathrm{~s}$, respectively; the corresponding mean pain threshold values in the diabetic control group were $20.46 \pm 1.63$ $\mathrm{s}, 19.45 \pm 1.33 \mathrm{~s}, 22.65 \pm 2.13 \mathrm{~s}, 20.12 \pm 1.28 \mathrm{~s}$, and $18.79 \pm 1.49 \mathrm{~s}$ (Table 2).

The mean pain threshold values following the administration of low-dose NT-4 were $18.65 \pm 1.45 \mathrm{~s}$, $19.30 \pm 1.86 \mathrm{~s}, 19.98 \pm 0.53 \mathrm{~s}, 19.63 \pm 0.44 \mathrm{~s}, 20.35 \pm$ $1.23 \mathrm{~s}, 19.98 \pm 0.61 \mathrm{~s}, 19.45 \pm 0.50 \mathrm{~s}, 20.68 \pm 1.64 \mathrm{~s}$, $20.55 \pm 0.38 \mathrm{~s}, 19.90 \pm 1.57 \mathrm{~s}$, and $20.45 \pm 0.49 \mathrm{~s}$, respectively; the corresponding mean pain threshold values following the administration of high-dose NT-
4 were $23.15 \pm 2.16 \mathrm{~s}, 29.98 \pm 2.49 \mathrm{~s}(p=0.002)$, $23.92 \pm 2.59 \mathrm{~s}, 26.60 \pm 3.18 \mathrm{~s}, 24.78 \pm 1.19 \mathrm{~s}(p=$ $0.026), 25.02 \pm 1.14 \mathrm{~s}(p=0.021), 22.83 \pm 1.19 \mathrm{~s}(p=$ $0.045), 23.65 \pm 0.65 \mathrm{~s}(p=0.02), 26.23 \pm 2.25 \mathrm{~s}(p=$ $0.008), 25.57 \pm 1.05 \mathrm{~s}(p=0.005)$, and $25.52 \pm 1.35 \mathrm{~s}$ $(p=0.001)$ (Table 2). Compared to the low-dose group, the high-dose group showed maximum response at $1 \mathrm{~h}$ (pain threshold value: $29.98 \pm 2.49$ ) and although a decrease in pain threshold values was observed in the following hours, the mean values were maintained at the same level with a significant difference (day 7: 25.52 $\pm 1.35, p=0.001)(p<0.05$; Table 2, Figure 3).

The averages of time-dependent responses to heat (pain threshold values) were compared between the mice in the healthy control groups and healthy diabetic groups (Figure 2) and then between those in the lowand high-dose groups (Figure 3). 


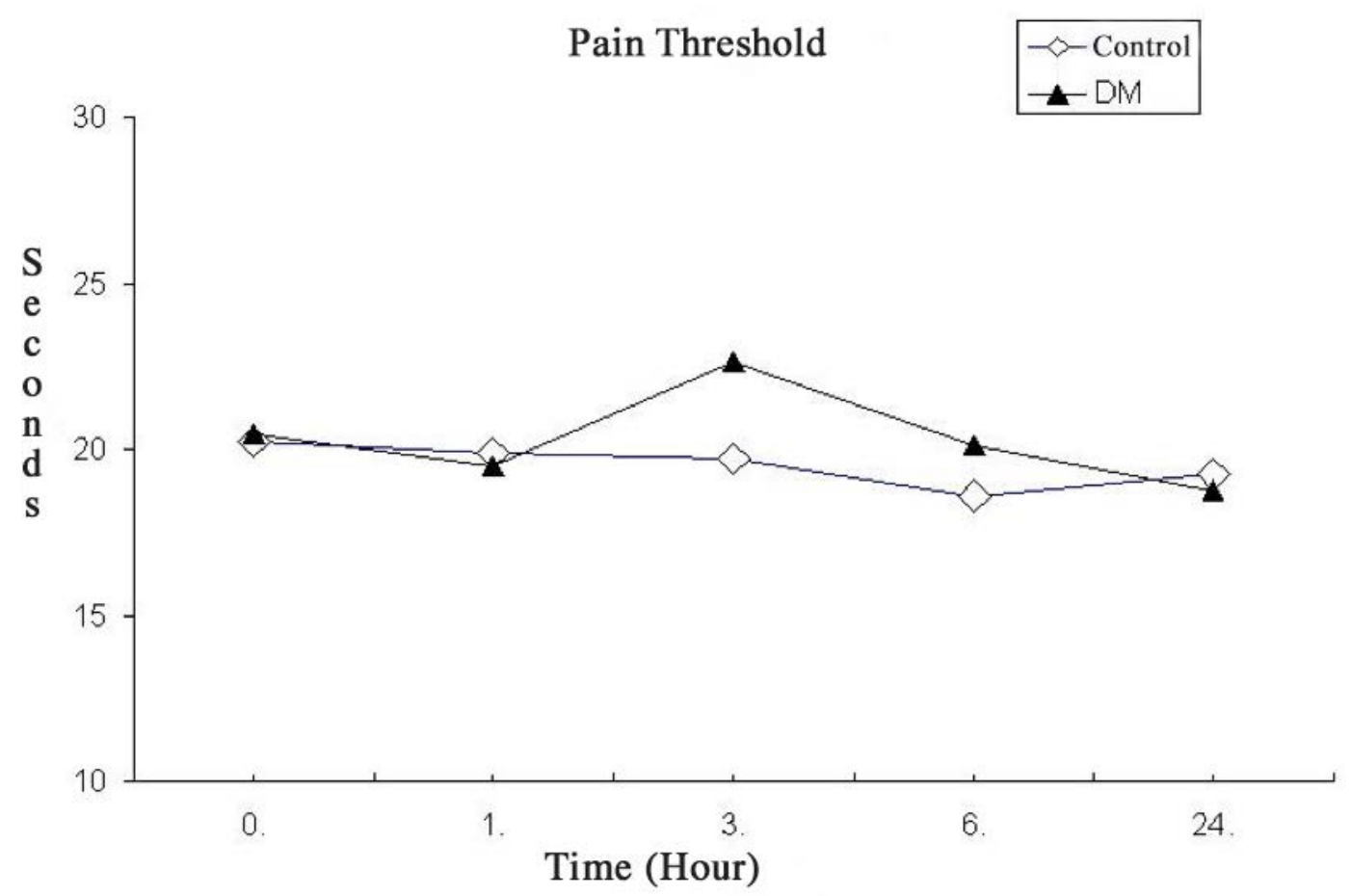

Figure 2. The comparison of mean pain threshold values between the healthy control group and diabetic control group ( $p<0.05$ ). $\mathrm{DM}=$ Diabetes mellitus group

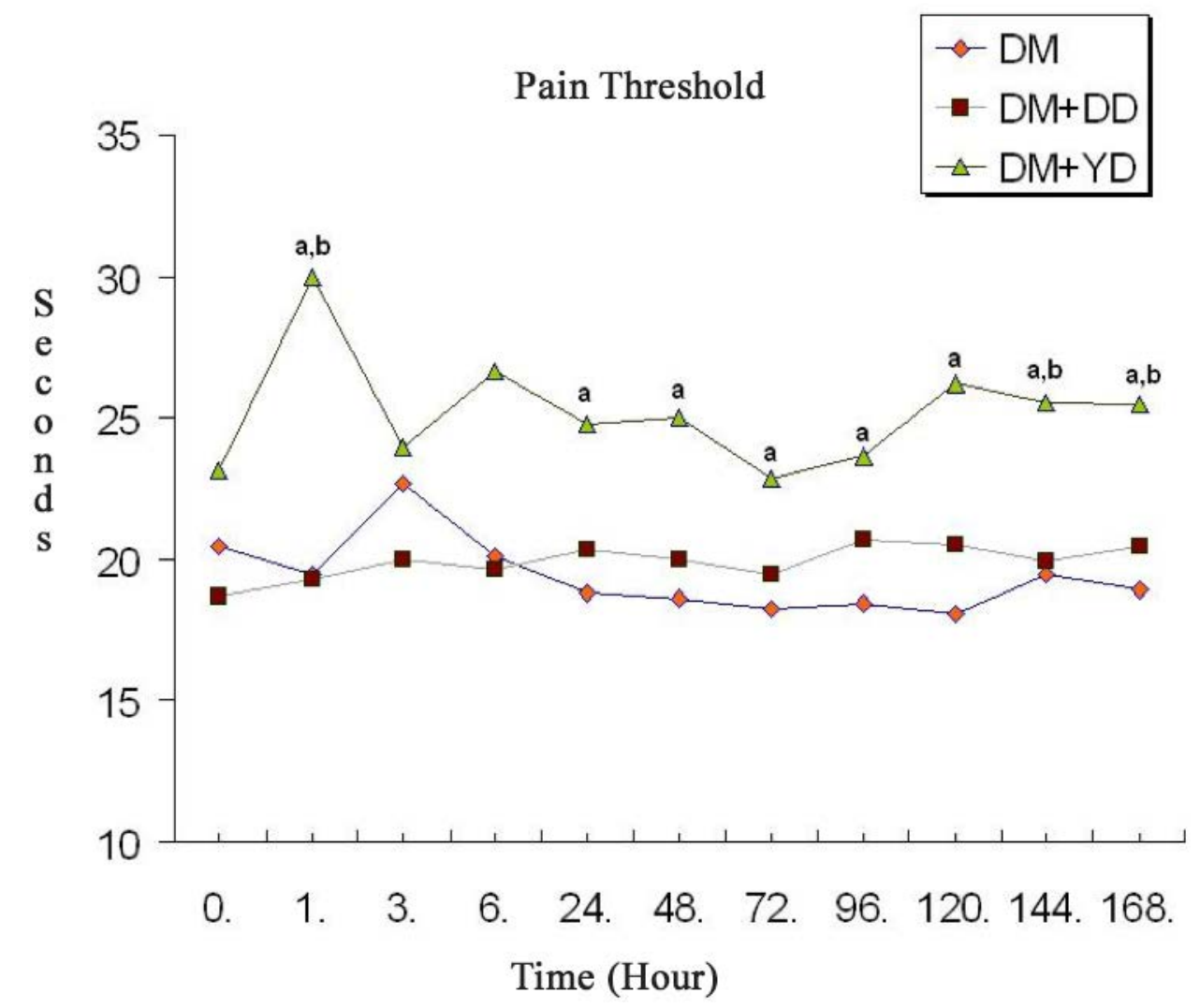

Figure 3. Comparison of the mean pain threshold values between the DM, DM + LD, and DM + HD groups $(p<0.05)$. DM $=$ Diabetes mellitus group, DM+LD =: Diabetes mellitus + low-dose neutrophin-4 group, DM+HD = Diabetes mellitus + high-dose neutrophin-4 group. The pain threshold values in the low-dose group did not vary across the DM and healthy control groups. aSignificant difference compared to the DM group $(p<0.05)$, bSignificant difference compared to the DM+LD group $(p<0.05)$ 


\section{DISCUSSION}

Diabetic neuropathy is a chronic complication that seriously affects the quality of life of diabetic people; it occurs in $60-70 \%$ of patients with symptoms including spontaneous pain, hyperalgesia, and diminished sensation [11, 12]. Currently, the only effective therapy to prevent or retard the development of diabetic neuropathy and alleviate its symptoms is glucose control and pain management [13]. Recently, some new antiepileptic agents have been reported to be good for neuropathic pain. However, an optimal treatment has not been developed yet.

STZ administration to mice and rats is widely performed to induce diabetic neuropathy $[14,15]$. In STZ-induced diabetic mice, hyperalgesia begins to develop at day 8 after STZ injection and lasts for at least four weeks [16]. STZ impairs pain threshold responses in diabetic mice by increasing the action potential of $\mathrm{C}$ fibers [17]. In our study, we induced diabetes and hyperalgesia at a dose and within the period stated in the literature using $180 \mathrm{mg} / \mathrm{kg} \mathrm{STZ}$.

Studies on pain threshold in diabetic mice have yielded controversial results. Among mechanical hyperalgesia studies, one large series demonstrated a $30-40 \%$ decrease in nociceptive threshold values [18]. Increased hypersensitivity responses have been observed in experimental models created with formalin injection $[19,20]$. Changes in thermal nociceptive threshold values observed in hyperalgesia considerably varied across studied models [21, 22].

In experimental animal models, among nociceptive test models, the hot plate and tail-flick tests are used to evaluate thermal acute pain responses. The tail-flick test is performed by touching a $16.5-\mathrm{V}$ heat source to a rat's tail. The baseline value is $20 \mathrm{~s}$ in the hot plate test and $12 \mathrm{~s}$ in the tail-flick test. The mechanical pain test is another nociceptive test performed by applying pressure to a rat's hind paws [23]. The hot plate test is an indirect in vivo method; results are quantitatively evaluated. It has been reported that pain threshold responses help obtain indirect information on diabetic neuropathic pain [18]. In our study, we used the hot plate test.

As the neuroprotective roles of neurotrophic factors against damage to sensory neurons have been revealed, this has necessitated determining whether these agents are effective for treating neuropathic pain.
Glial cell line-derived neuropathic factor is one of these agents showing analgesic effects in the treatment of experimental neuropathy by suppressing the afferent ectopic activity [4-7].

Most neurotrophic factors have been discovered because of their effects on specific neural populations in the peripheral nervous system. It has been proved that some of these factors are beneficial in the treatment of diabetic peripheral neuropathy. Most members of the neuropathic gene family (NGF, BDNF, NT-3 and NT-4/5, insulin-like growth factor [IGF]-1, IGF-II, and glial cell line-derived neurotrophic factor) have been extensively studied in animal models of diabetic neuropathy and have shown encouraging results. Recombinant human nerve growth factor was tested in phase II clinical experiments in the treatment of diabetic patients [24].

NT-4 is primarily effective on peripheral sensory neurons as well as many other neurons such as cortical, hippocampal, and basal forebrain cholinergic neurons. NT-4 is synthesized in the form of a $30 \mathrm{kDa}$ precursor protein and is transformed to a $13-\mathrm{kDa}$ mature form [25]. In our study, we used the newly discovered NT-4 belonging to a family of neurotrophic factors that has rarely been studied in the literature. Studies in diabetic animal models have yielded similar evidence to that obtained from diabetic human subjects with regard to the contribution of neurotrophic factors in the pathogenesis of diabetic peripheral neuropathy. In both in vivo and animal models of neuropathy conducted using NT-4, NGF, NT-3, IGF-1 and IGF-II, it has been demonstrated that these factors improve nerve degeneration [26].

Christianson et al. [8] evaluated behavioral responses to different harmful stimuli in the treatment of STZ-induced diabetic mice. The differences in responses to harmful heat (radiant heat), cold (acetone), and harmful mechanical stimuli applied to the hind paws of nondiabetic and diabetic mice were evaluated. NGF and glial cell line-derived neurotrophic factor) were administered intrathecally to three-week-old mice to determine whether the NT therapy normalizes neuropathic deficits. The mice receiving NT therapy were also compared with diabetic mice receiving insulin for three weeks. It was determined that both NGF and insulin therapy improved the mechanical and chromegenic behaviors of mice. Therefore, the sensitivity caused by 
mechanical and chemical stimuli was decreased in diabetes-induced mice and the dorsal root ganglion nerves of diabetic mice gave response to NGF or glial cell line-derived neurotrophic factor therapy [8]. In our study, the treatment was not administered to STZinduced diabetic mice. The animals with a blood glucose level between 200 and $500 \mathrm{mg} / \mathrm{dL}$ were included in the study. It was reported that the pain threshold significantly increased particularly in mice receiving high dose NT-4.

Akkina et al. [27] administered nonpeptidergic unmyelinated primary afferents rescue therapy of glial cell line-derived neurotrophic factor in STZ-induced diabetic mice. Within a four-week period following diabetes induction, a decrease was detected in isolectin thiamine monophosphate (TMP) activity in lamina II of the lumbar dorsal horn, particularly on distal sciatic afferents in the medial area. It was found that TMP healed spinal deficits in central afferents and that that both glial cell line-derived neurotrophic factor and NGF/NT-4 may repair spinal deficits on nonpeptidergic afferents in STZ-induced diabetic mice receiving glial cell line-derived neurotrophic factor or NT-4/NGF for two weeks. The results demonstrated that the administration of both glial cell line-derived neurotrophic factor and NGF/NT-4 selectively improved diabetes-related deficits in the TMP subpopulation of sensitive diabetics with nonpeptidergic unmyelinated sensory neurons [27].

Apfel et al. [28] conducted a study on the effects of neurotrophic factors in peripheral neuropathy and demonstrated that these factors contribute to the pathophysiology and treatment of various types of neuropathy, particularly of diabetic neuropathy; they suggested the efficacy of NT-3 in fibril neuropathy, of NT-4/5 IGF-1, CNTF and BDNF in motor neuron disease, and of NGF in small fibril sensory neuropathy [28].

In a randomized placebo controlled study conducted by Wellmer et al. [29], the subcutaneous administration of recombinant BDNF for three months improved the threshold values for cold sensation; this suggests that BDNF has some neuroprotective effects on neurons sensitive to thermal stimuli [29]. Siuciak et al. [30] found that NT-3 has an effect on spinal interneurons through a naloxone-sensitive mechanism. NT-3 triggered long-term analgesia in pathways involving serotonergic and opioid mechanisms when it was injected at the midbrain level [30].

As there are a very limited number of studies investigating the role of NT-4 on the development of spinal pain, we cited studies conducted using NT-4 and other members of the NT gene family having effects and structures similar to NT-4 (NGF, BDNF, CNTF, glial cell line-derived neurotrophic factor, NT-3, NT5 ) in the discussion section. In our study, we referred to papers using BDNF and NGF along with NT-4 as NGF structurally resembles NT-4 and BDNF shows an effect over tyrosine kinase B receptor as NT-4. Most studies have been conducted using NGF, which was the first neurotrophic factor to be discovered; studies on the recently discovered NT-3and NT 4/5 are still continuing, and we suggest that there is a need for determining the efficacy of these recently discovered neurotrophic factors in experimental and clinical studies using different pain models and different doses.

In line with the literature, the present study found that recombinant human NT-4 at a dose of $3 \mathrm{mg} / \mathrm{kg}$ (high dose) significantly increased pain threshold values in the hot plate test, which measures pain threshold values for acute thermal stimuli; however, these effects did not occur at low doses $(0.3 \mathrm{mg} / \mathrm{kg})$. The hot plate test was performed with the aim of investigating the effects of neurotrophic factors on painful diabetic neuropathy in STZ-induced diabetic mice and the following are the important findings of the present study: Hyperglycemia was induced to an extent that would lead to diabetic neuropathy. The period of time required to develop diabetic neuropathy was completed. The pain threshold values in the lowdose group were not different than from those in the diabetic control and healthy control groups (Table 2, Figure 2). An increase was observed in the hot plate pain threshold values in the high-dose group compared to that in the healthy control group, diabetic control group, and low dose group; this difference reached statistical significance $(p<0.05$, Table 2 , Figure 3$)$.

\section{CONCLUSION}

In conclusion, neurotrophic factors (neurotrophin4) have been shown to be effective on painful diabetic 
neuropathy in streptozocin-induced diabetic rats. However, there is a need for larger-scale and longerterm studies for clinical use.

\section{Conflict of interest}

The authors disclosed no conflict of interest during the preparation or publication of this manuscript.

\section{Funding Statement}

This work was partially supported by grants from Frrat University School of Medicine.

\section{REFERENCES}

[1] Chawla A, Chawla R, Jaggi S. Microvasular and macrovascular complications in diabetes mellitus: Distinct or continuum. Indian J Endocrinol Metab 2016;20:546-51.

[2] Davon A. M, Chronic pain. A primary Care Guide to Practical Management, second ed., Human Pres: Totawa, NJ. 2005;114-5. [3] Price RD, Milne SA, Sharkey J, Matsuoka N, Advances in small molecules promoting neurotrophic function. Pharmacol Ther 2007;115:292-306.

[4] Bennett DL. Neurotrophic factors important regulators of nociceptive function. Neuroscientist 2001;7:13-7.

[5] Skaper SD. The neurotrophin family of neurotrophic factors: an overview. Methods Mol Biol 2012;846:1-12.

[6] Kerr BJ, Bradbury EJ, Bennett DL, Trivedi PM, Dassan P, French J, et al. Brain-derived neurotrophic factor modulates nociceptive sensory inputs and NMDA-evoked responses in the rat spinal cord. J Neurosci 1999;19:5138-48.

[7] Chen SQ, Cai Q, Shen YY, Cai XY, Lei HY. Combined use of $\mathrm{NGF} / \mathrm{BDNF} / \mathrm{bFGF}$ promotes proliferation and differentiation of neural stem cells in vitro. Int J Dev Neurosci 2014;38:74-8.

[8] Christianson JA, Ryals JM, McCarson KE, Wright DE. Beneficial actions of neurotrophin therapy on diabetes-induced hypoalgesia in mice. J Pain 2003;4:493-504.

[9] Christianson JA, Ryals JM, Johnson MS , Dobrowsky RT, Wright DE. Neurotrophic modulation of myelinated cutaneous innervation and mechanical sensory loss in diabetic mice. Neuroscience 2007;145:303-13.

[10] Handwerker HO, Kobal G. Psychophysiology of experimentally induced pain. Physiol Rev 1993;73:639-71.

[11] Deli G, Bosecyak E, Pusch G, Komoly S, Feher G. Diabetic neuropathies: diagnosis and management. Neuroendocrinology 2013;98:267-80.

[12] Vinik AI, Park TS, Stansberry K B, Pittenger GL. Diabetic neuropathies. Diabetologia 2000;43;957-73.

[13] Callaghan BC, Cheng HT, Stables CL, Smith AL, Feldman EL. Diabetic neuropathy: clinical manifestations and current treatments. Lancet Neurol 2002;11:521-34.

[14] Rees DA, Alcolado JC. Animal models of diabetes mellitus. Diabet Med 2005;22:359-70.

[15] Malik RA. Current and future strategies for the management of diabetic neuropathy. Treat Endocrinol 2003;2:389-400.

[16] Ahlgren SC, Levine JD. Mechanical hyperlgesia in streptozocin diabetic rat is not sympathetically maintained. Brain Res 1993;616:171-5.

[17] Ahlgren SC, White DM, Levine JD. Increased responsiveness of sensory neurons in the saphenous nerve of the streptozotocin-diabetic rat. J Neurophysiol 1992;68:2077-85.

[18] Piercy V, Banner SE, Bhattacharyya A, Parsons AA, Sanger GJ, Smith SA, et al. Thermal but not mechanical, nociceptive behavior is altered in the Zucker Diabetic Fatty rat and is independent of glycemic status. J Diabetes Complications 1999;13:163-9.

[19] Zhuang HX, Secyder CK, Pu SF, Ishii DN. Insulin-like growth factors reverse or arrest diabetic neuropathy: effects on hyperalgesia and impaired nerve regeneration in rats. Exp Neurol 1996;140:198-205.

[20] Calcutt NA, Jorge MC, Yaksh TL, Chaplan SR. Tactile allodynia and formalin hyperalgesia in streptozotocin-diabetic rats: effects of insulin, aldose reductase inhibition and lidocaine. Pain 1996;68 293-9.

[21] Fox A, Eastwood C, Gentry C, Manning D, Urban L. Critical evaluation of the streptozotocin model in the rat. Pain 1999;81:307-16.

[22] Raz I, Hasdai D, Seltzer M, Melmed RN. Effect of hyperglycemia on pain perception and on efficacy of morphine analgesia in rats. Diabetes 1988;37:1253-9.

[23] Klitgaard H, Matagne A, Gobert J, Wülfert E. Evidence for a unique profile of levetiracetam in rodent models of seizures and epilepsy. Eur J Pharmacol 1998;353:191-206.

[24] Apfel SC. Neurotrophic factors in the therapy of diabetic neuropathy. Am J Med 2000;107:34-42.

[25] Schuman EM. Neurotropin regulation of synaptic transmission. Curr Opin Neurobiol 1999;9:105-9.

[26] Apfel SC. Neurotrophic factors and diabetic peripheral neuropathy. Eur Neurol 1999;41:27-34.

[27] Akkina SK, Patterson CL, Wright DE. GDNF rescues nonpeptidergic unmyelinated primary afferents in streptozotocintreated diabetic mice. Exp Neurol 2001;167:173-82.

[28] Apfel SC, Kessler JA. Neurotrophic factors in the therapy of peripheral neuropathy, Baillieres Clin Neurol 1995;4:593-606.

[29] Wellmer A, Misra VP, Sharief MK, Kopelman PG, Anand P. A double-blind placebo-controlled clinical trial of recombinant human brain-derived neurotrophic factor (rhBDNF) in diabetic polyneuropathy. J Peripher Nerv Syst 2001;6:204-10.

[30] Siuciak JA, Wong V, Pearsall D, Wiegand SJ, Lindsay RM. BDNF produces analgesia in the formalin test and modifies neuropeptide levels in rat brain and spinal cord areas associated with nociception. Eur J Neurosci 1995;7663-70. 